\title{
(183)
}

\section{Composition and Functional Diversity of the Avifaunal Community at an Urban Landfill in Colombo District, Sri Lanka}

\author{
S.S. Marasinghe $^{1 *}$, P.K.P. Perera ${ }^{1}$, N.P. Dayawansa ${ }^{2}$ \\ ${ }^{I}$ Department of Forestry and Environmental Science, University of Sri Jayewardenepura, Sri Lanka \\ ${ }^{2}$ Department of Zoology, University of Colombo, Sri Lanka \\ sumudumarasinghe@gmail.com
}

\begin{abstract}
Putrescible waste landfills in urban settings are known to attract large number of birds. As these man-made ecosystems are reliable and rich sources of food, they can support large communities of avifauna belonging to different feeding guilds. Studies conducted elsewhere have identified putrescible waste landfills as the primary cause for increased abundance of certain bird species in local and regional scale, as the carrying capacity has reached new levels due to ample availability of food within landfills. Although birds on landfills perform valuable ecological functions, unusually high population inflations of few bird species can have severe impacts on the overall ecological balance. On the other hand, birds may cause conflicts with human interest with respect to noise, birds carrying litter off site, possible transmission of pathogens in bird droppings, pollution of water near roosting sites due to droppings, and increased risks of bird-strikes/collisions. As any major changes in waste management and disposal practices on landfills can potentially have sizeable impacts on bird populations dependent on landfills, better understanding on the extent and patterns of daily use of landfills by birds and dynamics in abundance of birds is highly important.
\end{abstract}

The abundance of birds was estimated in the study at Karadiyana landfill, an urban landfill located between Thumbowila and Werahera in Kesbewa D.S. Division, Colombo. Bird censuses were performed using block counts in two different sites on the landfill, i.e., active dumping area and inactive dumping area, during the period of April to September 2015. 24,553 individual birds are recorded belonging to 20 species and 12 families with Cattle Egret (Bubulcus ibis), House Crow (Corvus splendens), Feral Pigeon (Columba livia) and Common Mynah (Acridotheres tristis) being the most abundant. Abundance and density of birds was much higher in the active dumping area. However, the inactive dumping area accounted for the highest avifaunal diversity (Shannon-Wiener index: $\mathrm{H}^{\prime}=1.81$ ) and species richness (Margalef's index=1.39). The abundance of Cattle Egret, House Crow, Feral Pigeon, Common Mynah, Black headed Ibis, and Brahminy Kite was significantly high in active dumping area $(p<0.05)$. This suggests the ample availability of food sources for these species in the active dumping area. Feeding guild comparisons between the two sites further indicated that the active dumping area is dominated by omnivores $(t=5.876, \mathrm{p}=0.000)$, followed by carnivores $(t=2.996, \mathrm{p}=0.003)$. Carnivore feeding guild in the active dumping area mainly represented by migratory Cattle Egret population seems to be replaced by omnivores with the onset of migration by Cattle Egrets, indicating possible feeding overlaps and competition among species.

Keywords: Avifaunal diversity, Urban landfills, Feeding guilds, Abundance, Karadiyana landfill 